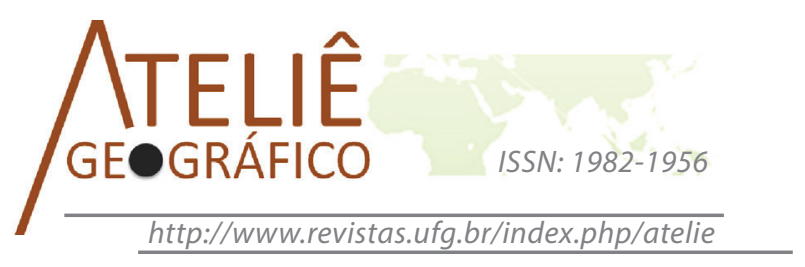

\title{
Sistemas ambientais e indicadores de desertificação: dinâmica das paisagens semiáridas na sub-bacia hidrográfica do riacho Santa Rosa
}

\author{
Environmental systems and indicators desertification: \\ dynamics of semi-arid landscapes in the watershed of the \\ creek Santa Rosa
}

\author{
Sistemas ambientales e indicadores desertificación: \\ dinámica de los paisajes semi áridas de la sub-cuenca de \\ la corriente Santa Rosa
}

Luis Ricardo Fernandes da Costa

Universidade Federal do Ceará

ricardogeoufc@yahoo.com.br
Vládia Pinto Vidal de Oliveira
Universidade Federal do Ceará
vladia.ufc@gmail.com

\begin{abstract}
Resumo
Com o desenvolvimento de estudos ambientais integrados, têm-se uma crescente busca por meios que estabeleçam parâmetros qualitativos e quantitativos no âmbito da degradação e/ou desertificação. O trabalho, com base nos estudos integrados, discute elementos que proporcionam subsídios para o diagnóstico ambiental integrado, além de caracterizar os sistemas ambientais e aplicar os indicadores de desertificação. As bases conceituais estão elencadas na concepção holística, orientada para uma visão integrativa dos elementos da paisagem. Do ponto de vista metodológico o trabalho foi executado em cinco etapas: análise de material bibliográfico, cartográfico e imagens de satélite; produção de mapas para auxílio no campo; trabalhos de campo para a comprovação dos dados; correção e adequação do material cartográfico produzido e aplicação dos indicadores de desertificação na sub-bacia. Os sistemas ambientais caracterizados pelos sertões ainda são as áreas mais vulneráveis à desertificação do ponto de vista geoambiental, com o agravante das áreas historicamente utilizadas para a subsistência local.

Palavras-chave: Paisagem semiárida. Sistemas Ambientais. Indicadores de desertificação. Sub-bacia hidrográfica do Riacho Santa Rosa.
\end{abstract}




\begin{abstract}
With the development of integrated environmental studies have been increasingly looking for ways to establish qualitative and quantitative parameters within the degradation and / or desertification. The work, based on integrated studies, discusses elements that provide grants for environmental assessment, as well as identifies and characterizes the environmental systems, in addition to analyzing the desertification indicators. The conceptual bases are listed in the holistic approach, geared towards an integrative view of landscape elements. From a methodological point of view, the work was carried out in five stages: bibliographical material analysis, mapping and satellite imagery; production of maps to aid in the field; fieldwork for the verification of the data; correctness and appropriateness of the produced cartographic material and application of desertification indicators in the sub-basin. Environmental systems characterized by hinterlands are still the most vulnerable areas to the desertification of the environmental point of view, with the aggravation of the areas traditionally used for local livelihoods.
\end{abstract}

Keywords: semiarid landscape. Environmental Systems. Indicators of desertification. Sub-basin of the Santa Rosa Creek.

\begin{abstract}
Resumen
Con el desarrollo de estudios ambientales integrados han estado buscando cada vez más maneras de establecer parámetros cualitativos y cuantitativos dentro de la degradación y /o la desertificación. El trabajo, basado en estudios integrados, analiza los elementos que proporcionan subvenciones para la evaluación ambiental, así como identifica y caracteriza a los sistemas ambientales, además de analizar los indicadores de desertificación. Las bases conceptuales se enumeran en el enfoque integral, orientado a una visión integradora de los elementos del paisaje. Desde el punto de vista del trabajo se llevó a cabo en cinco etapas metodológicas: análisis de material bibliográfico, la cartografía y las imágenes de satélite; producción de mapas para ayudar en el campo; el trabajo de campo para la verificación de los datos; corrección y adecuación del material cartográfico producido y aplicación de indicadores de desertificación en la sub-cuenca.. Sistemas ambientales caracterizadas por zonas de sertões siguen siendo las zonas más vulnerables a la desertificación del punto de vista geo-ambiental, con el agravante de las áreas tradicionalmente utilizados para los medios de vida locales.
\end{abstract}

Palabras clave: paisaje semiárido. Sistemas Ambientales. Los indicadores de la desertificación. Sub-cuenca del corriente Santa Rosa.

\title{
Introdução
}

No estado do Ceará, a degradação dos recursos naturais tem alcançado altos índices, reflexo do avanço da desertificação. Com cerca de $92 \%$ do território sob condições de semiaridez (CEARÁ, 2010), adquire uma situação de degradação dos recursos naturais, principalmente na área dos sertões, inviabilizando a capacidade de resiliência da natureza (OLIVEIRA, 2006).

O clima semiárido do estado do Ceará é caracterizado por condições de temperaturas regulares e intensa insolação durante o ano. Médias térmicas sempre superiores a $26^{\circ} \mathrm{C}$, com pluviometria variada, possuindo uma estação chuvosa de 3 a 5 meses por ano, com períodos de 7 a 9 meses secos por ano, com uma isoieta que varia de 500 a 800 mm (SOARES et al., 1995). 
A drenagem com padrão dendrítico resulta da impermeabilidade das litologias que facilitam o escoamento superficial. Os solos, apesar de possuírem fertilidade média a alta, são em geral rasos, necessitando de um manejo adequado para seu melhor proveito agropastoril. A vegetação típica das caatingas predomina, com exceções para área com condições hídricas mais favoráveis, a destacar as áreas de inundação sazonal, com ocorrência de mata ciliar de carnaubais (SOARES et al., 1995).

Com essas características naturais do semiárido, resultado da irregularidade e incerteza das chuvas, o Estado do Ceará apresenta uma área extremamente vulnerável do ponto de vista social e ambiental, necessitando de estudos que possibilitem uma melhor compreensão da dinâmica socioambiental.

Para tanto, o trabalho tem como objetivo analisar a implicação dos indicadores de desertificação nos sistemas ambientais da sub-bacia hidrográfica do riacho Santa Rosa (figura 1).

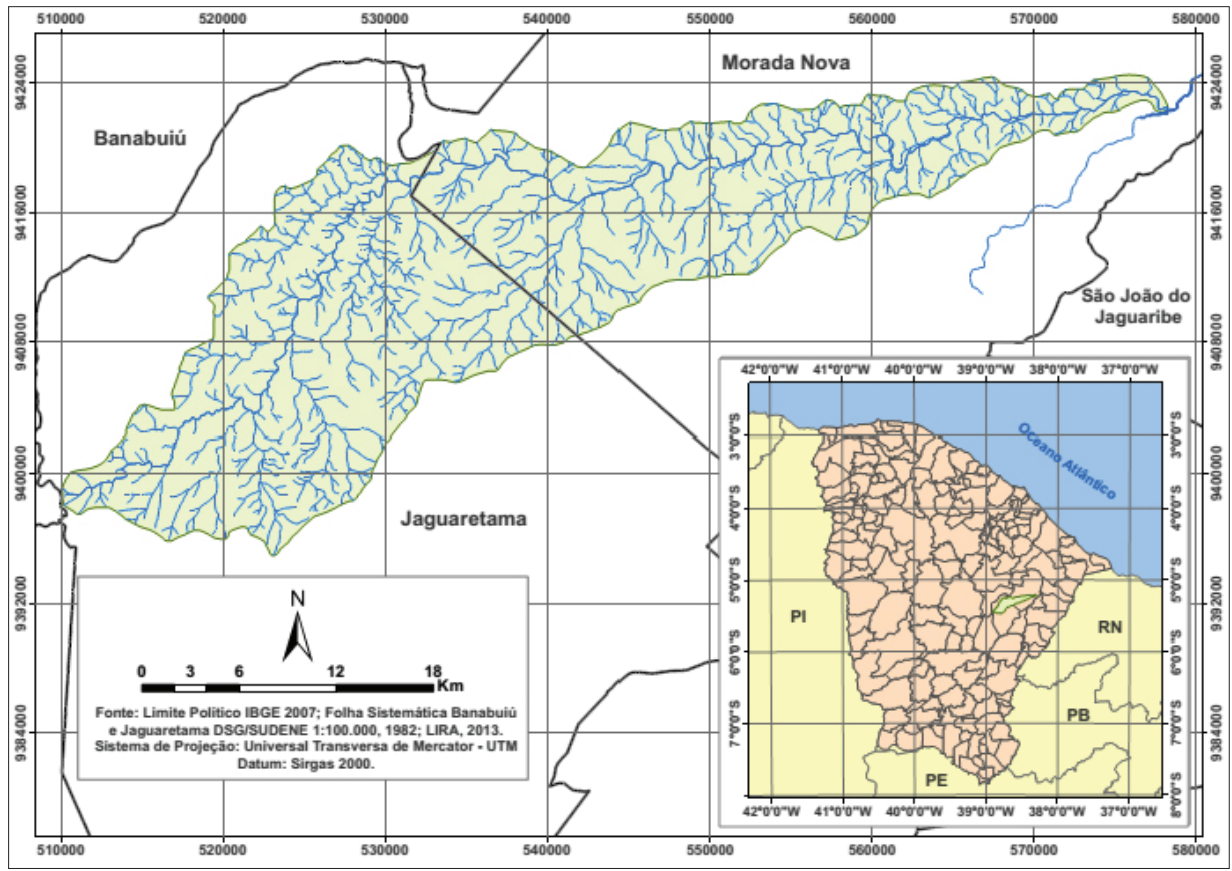

Figura 1. Localização da sub-bacia hidrográfica do riacho Santa Rosa. Fonte: Elaborado pelos autores.

A aplicação sistêmica norteou o desenvolvimento do trabalho, onde foram analisadas as condições biofísicas da sub-bacia. A partir do diagnóstico ambiental e da análise dos componentes naturais como geologia, geomorfologia, clima, hidrologia de superfície, solos e cobertura vegetal, além dos padrões de uso e ocupação do solo, foram delimitados os sistemas ambientais. 


\section{Procedimentos metodológicos}

A pesquisa utilizou-se da análise sistêmica, uma vez que esta procura compreender a paisagem a partir da combinação dinâmica entre seus elementos (físicos e antrópicos). Além disso, também foram agregadas as discussões referentes às técnicas do sensoriamento remoto, para que dessa forma o trabalho adquirisse maior qualidade no que se refere ao geoprocessamento como ferramenta na análise ambiental.

Para a confecção dos mapas foram utilizadas as cartas da Superintendência de Desenvolvimento do Nordeste SUDENE, mais precisamente as folhas Banabuiú e Jaguaretama; Cartas do projeto RADAM BRASIL (1981); Atlas do Ceará, da Fundação Instituto de Pesquisa e Informação do Ceará IPLANCE (1989), assim como dados do Instituto de Pesquisa e Estratégia Econômica do Ceará (IPECE), e a Fundação Cearense de Meteorologia e Recursos Hídricos (FUNCEME).

Utilizaram-se duas imagens de satélite, Landsat 8/OLI datadas respectivamente dos dias 23 de maio de 2013 e 8 de junho de 2013, com o objetivo de analisar os aspectos geoambientais e os principais padrões de uso da sub-bacia hidrográfica do riacho Santa Rosa.

Foi utilizado o Software Arcgis 10 (licença disponível no departamento de Geografia da Universidade Federal do Ceará) para a produção dos mapas; imagens de satélite Landsat 8, com a utilização das bandas 6, 5 e 4, combinação necessária para a visualização dos diferentes tons de verde, corpos d'água e bancos de sedimentos, aspecto importante para análise dos componentes ambientais das imagens; dados da Shuttle Radar Topography Mission (SRTM) da National Aeronautics and Space Administration (NASA), obtidas através da Empresa Brasileira de Pesquisa Agropecuária (EMBRAPA), além de computadores para o processamento dos dados.

Trabalhos de campo, registro fotográfico e coleta de materiais (amostras de rocha e solo) foram sucessivamente realizados para validação dos dados. Os trabalhos de campo foram realizados no segundo semestre de 2012 e primeiro semestre de 2013.

Para a produção do mapa de sistemas ambientais foi utilizado o componente geomorfológico como critério inicial, seguido das classes de solos para uma melhor apreensão das variações da depressão sertaneja (sertões).

Os padrões de uso e ocupação da terra foram identificados a partir da pesquisa bibliográfica, cartográfica e dos trabalhos de campo. Para estipular a vulnerabilidade ambiental da área, utilizou-se da proposta de Souza (2000), em que se podem estabelecer parâmetros para determinar a estabilidade e instabilidade do ambiente, com base em Tricart (1977).

Para a avaliação do grau de desertificação na área, foram selecionados 6 indicadores geobiofísicos de desertificação (tabela 1), com o intuito de estabelecer uma relação entre as diversas variáveis geoambientais que pudessem ser mensuradas como indicador. Os índices foram organizados de 1 a 5, pressupondo que os maiores valores correspondem às melhores potencialidades para a conservação. 
Tabela 1. Indicadores geobiofísicos de desertificação selecionados.

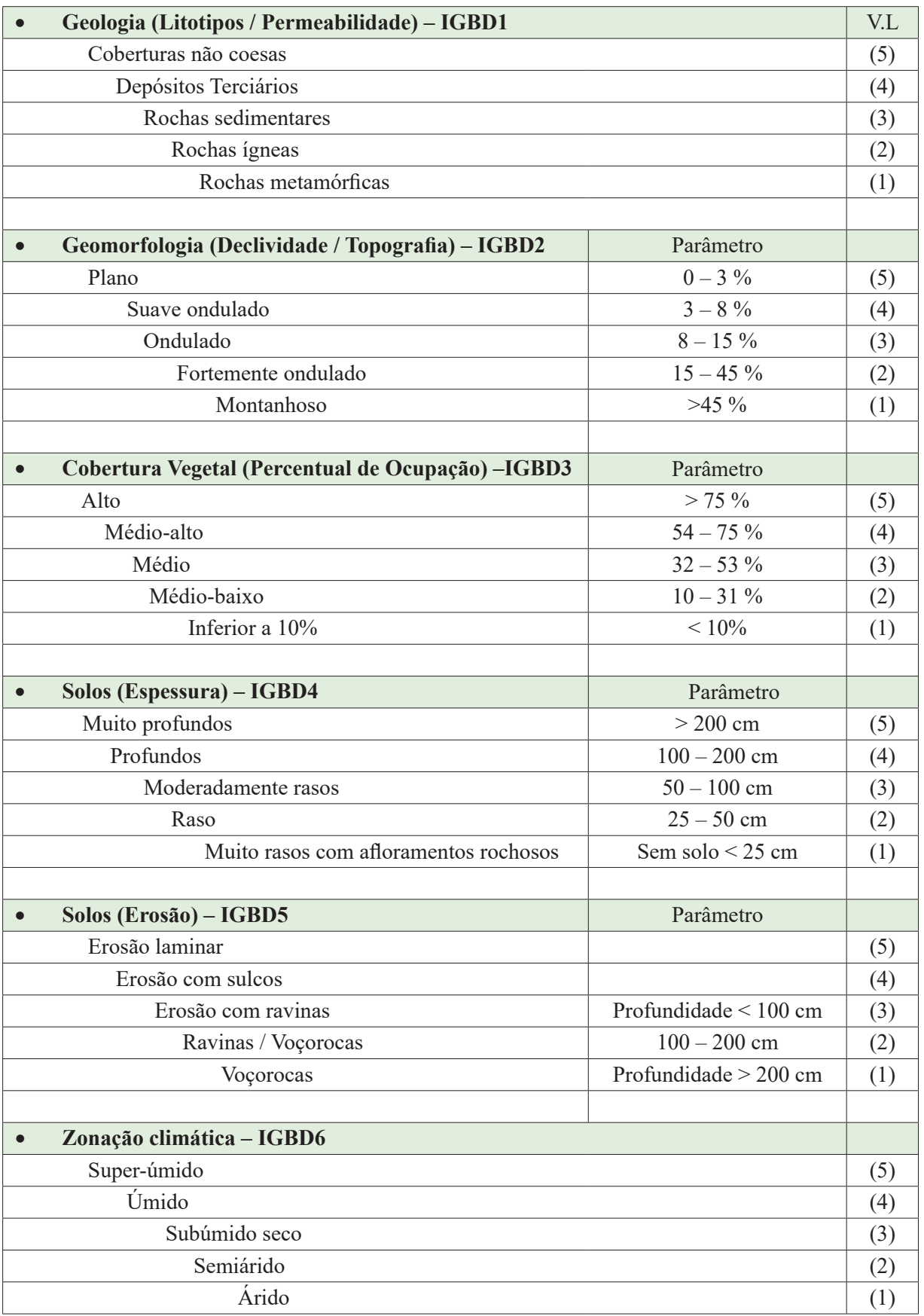

Fonte: Adaptado de Oliveira (2012); Costa (2014). 


\section{Sistemas ambientais e a bacia hidrográfica como âncora para os estudos integrados}

As bases conceituais do trabalho são estabelecidas em grande parte nos trabalhos que envolvem a esfera ambiental, ou seja, que estabelecem a visão sistêmica na qual têm-se como referencial teórico autores como Bertalanffy (1973), Bertrand (1971), Tricart (1977, 1981), Christofoletti (1999), Souza (2000), e Souza e Oliveira (2011), que contribuem para as bases teóricas e metodológicas do trabalho, além de ressaltar o esforço para o manuseio dos elementos que envolvem a análise sistêmica, pautada em sua grande esfera nos estudos da Geografia física.

Tal concepção geossistêmica estaria atrelada à categoria geográfica ao qual o trabalho tem base, ou seja, a concepção de Paisagem, que no contexto do trabalho baseiase em compreendê-la não apenas como uma simples adição de elementos geográficos desconexos, e sim como uma determinada porção do espaço, resultado da combinação dinâmica, portanto instável, de elementos físicos, biológicos e antrópicos que, reagindo dialeticamente uns sobre os outros, fazem da paisagem um conjunto único e indissociável, em perpétua evolução (BERTRAND, 1971).

Os sistemas ambientais representam entidades organizadas na superfície terrestre, onde sua espacialidade se torna uma característica fundamental e necessária. (CHRISTOFOLETTI, 1999).

A análise geoambiental em tal contexto procura fundamentar-se como um instrumento para a análise sistêmica. A identificação e hierarquização dos componentes são de fundamental importância para o sucesso na análise dos sistemas ambientais, assim como aponta os autores:

Os sistemas ambientais são identificados e hierarquizados conforme a interrelação dos seus componentes geoambientais, suas dimensões e características de origem e evolução. Considerando a diversidade interna dos sistemas, são delimitadas as unidades elementares contidas em um mesmo sistema de relações que configura, espacialmente, os subsistemas. Sob esse aspecto, a concepção de paisagem assume significado para a delimitação das subunidades, em decorrência da exposição de padrões fisionômicos uniformes ou de relativa homogeneidade (SANTOS e SOUZA, 2014, p. 222 e 223).

Tal concepção é de fundamental importância para a identificação e descrição das unidades homogêneas da sub-bacia em estudo. $\mathrm{O}$ critério para a delimitação dos sistemas se pautou majoritariamente pela distribuição das classes de solo. Tal opção foi efetivada pela inexpressividade das classes de relevo, critério clássico para a delimitação de unidades geoambientais (SOUZA, 2007).

De tal modo, a bacia hidrográfica foi elemento utilizado para compreender os elementos biofísicos de forma integrada, utilizando-se desta como unidade de planejamento e gestão territorial.

A bacia hidrográfica pode ser concebida como célula básica de análise ambiental, permitindo conhecer e avaliar seus diversos componentes, processos e interações que 
nela ocorrem. A visão sistêmica e integrada do ambiente está implícita na adoção desta unidade fundamental (BOTELHO e SILVA, 2004).

A bacia hidrográfica, segundo Guerra e Guerra (1997), pode ser considerada como um conjunto de terras drenadas por um rio principal e seus afluentes. No entanto, é possível encontrar outras definições para a compreensão dessa célula de estudo e sua importância para os estudos integrados.

Os problemas enfrentados no planejamento dos recursos hídricos têm incitado cada vez mais a utilização de abordagens integradas, e como já foi dito anteriormente, a bacia de drenagem é uma dessas possibilidades.

Segundo Pires e Santos (1995), abordagens de planejamento e gerenciamento que utilizam a bacia hidrográfica como unidade de trabalho têm evoluído bastante. Os autores destacam ainda que:

As características biogeofísicas dessas bacias apresentam sistemas ecológicos e hidrológicos relativamente coesos. No início, o processo de gerenciamento e planejamento de bacia hidrográficas visa basicamente à solução de problemas relacionados à água, prioridade para o controle de inundações, para a irrigação, navegação ou para o abastecimento público e industrial (PIRES e SANTOS, 1995, p. 41).

Ainda segundo os autores, essa abordagem mais complexa busca solucionar conflitos entre os usuários e dimensionar a qualidade e quantidade de recursos que cabe a cada um, assim como suas responsabilidades sobre tais recursos (PIRES e SANTOS, 1995).

O conceito de bacia hidrográfica pode ser utilizado para a conservação de recursos naturais com a possibilidade de avaliar, em uma determinada área geográfica, o seu potencial de desenvolvimento e a sua produtividade biológica, determinando as melhores formas de aproveitamento dos mesmos, com o mínimo impacto ambiental (PIRES et al.,2005).

Bacias hidrográficas em regiões semiáridas ainda passam pelas intempéries naturais, ou seja, a irregularidade pluviométrica compromete muitas vezes o planejamento em áreas deste tipo. Tal agravante é maior em ambientes que muitas vezes não tem uma assistência às condições básicas de moradia, como saneamento básico, água potável e assistência saúde pública de qualidade.

Dentre as principais causas que ameaçam a qualidade ambiental em uma bacia hidrográfica, estão relacionadas às atividades não sustentáveis, com o objetivo de lucro imediato, que não computam os custos ambientais e sociais, repassando-os a terceiros (PIRES et al.,2005).

Para tanto, as abordagens de planejamento e gerenciamento que utilizam a bacia hidrográfica como unidade de trabalho têm evoluído bastante, pois as características biogeofísicas dessas bacias apresentam sistemas ecológicos e hidrológicos relativamente coesos (LORANDI e CANÇADO, 2005). 
Assim, a análise dos parâmetros físicos de uma bacia hidrográfica mostra-se como um caminho coerente para a análise e intervenção nesse sistema ambiental, a partir da concepção sistêmica.

\section{Caracterização da área}

Localizada na bacia do rio Banabuiú, no estado do Ceará, a sub-bacia hidrográfica do riacho Santa Rosa está localizada na porção centro-norte do estado do Ceará, com uma área de aproximadamente $675 \mathrm{Km}^{2}$. A compreensão de sub-bacia partiu da delimitação de Faustino (1996 apud Teodoro et al., 2007), onde este classifica sub-bacia com áreas maiores que $100 \mathrm{~km}^{2}$ e menores que $700 \mathrm{~km}^{2}$. O acesso à área pode ser feito através da $\mathrm{BR}$ 116 e posteriormente pela CE 371 .

A sub-bacia do riacho Santa Rosa compreende parte da bacia do rio Banabuiú. Esta última por sinal faz parte da bacia do rio Jaguaribe, que compreende $51,9 \%$ do Estado, com área aproximada de $75.669 \mathrm{Km}^{2}$ (CEARÁ, 2009).

A geologia da área é caracterizada pelo Complexo Jaguaretama, constituído de ortognaisses migmatizados, composição entre granito e tonalito, como paragnaisses, anfibolitos, quartzitos, metaultramáficas e rochas calcissilicáticas (CPRM, 2003).

Do ponto de vista geomorfológico, a área é caracterizada pela ocorrência de pedimentos (feições aplainadas que convergem através de declives suaves para os fundos de vales), influência principalmente da morfogênese mecânica (intemperismo físico), que trunca indistintamente as litologias do embasamento cristalino, elaborando assim a depressão sertaneja.

O clima regional, predominantemente semiárido, apresenta irregularidades pluviométricas temporo-espaciais. O regime pluviométrico é do tipo tropical com um curto período chuvoso e um prolongado período de estiagem. $\mathrm{O}$ índice de aridez ${ }^{1}$ para área da sub-bacia foi estabelecido através de dados secundários dos municípios de Jaguaretama e Morada Nova, onde os índices desses municípios são respectivamente de 0,44 e 0,43 (SOARES et al., 1995).

A irregularidade pluviométrica atinge máximos de estiagem, ocorrendo secas calamitosas e também chuvas excepcionais que provocam cheias, primordialmente nas áreas adjacentes aos grandes vales fluviais, como por exemplo, o caso do rio Jaguaribe (SOUZA et al., 2002).

Os solos da área são caracterizados pela ocorrência da Associação de Planossolos Solódicos, Neossolos Flúvicos e Neossolos Litólicos. Os solos da área de estudo têm essas características devido à sua relação com a Depressão Sertaneja, impulsionados pela escassez de recursos hídricos, provocando assim o baixo desenvolvimento dos perfis de solo. A vegetação é caracterizada pela ocorrência da caatinga arbustiva.

1. O índice estabelece o grau de aridez de determinada área. Com base nos estudos de Thornthwaite, esse índice deriva da razão entre a Precipitação (P) e da perda máxima possível de água por Evapotranspiração Potencial (ETP), o qual indica semiaridez quando se situa entre 0,50 e 0,21 . 
Considerando a agricultura temporária, os dois municípios apresentam razoável aptidão para as culturas de milho e feijão, destacando-se como grande produtor de arroz e feijão, o município de Morada Nova, em função do seu projeto de irrigação (CEARÁ, 2009).

A partir da análise dos atributos socioeconômicos é importante perceber quais as principais tipologias de uso que estão atuando na bacia e quais os principais impactos causados pelos agentes produtores do espaço na área. Como ressaltado anteriormente, a base produtiva na sub-bacia ainda continua calcada na agricultura e pecuária extensiva, principalmente nas comunidades mais distantes dos núcleos urbanos.

De acordo com Nascimento (2006), as tipologias de uso/ocupação da terra relacionam-se aos modelos de exploração dos recursos naturais e aos ativos ambientais em razão do seu valor econômico-social e das atividades exercidas em determinadas áreas como a agricultura, desenvolvimento urbano, turístico e industrial, e implantação de estrutura de base sofisticada.

Essas atividades em conjunto causam danos principalmente à cobertura vegetal e aos solos da região. Além da lenha para o consumo de muitas famílias, a produção de carvão foi observada na região, assim como as queimadas para o plantio.

Outro problema observado é o condicionamento do lixo, que muitas vezes, ou é lançado nas áreas adjacentes ou queimado, prática muito comum em muitas comunidades visitadas.

\section{Resultados e discussões}

\section{Os sistemas ambientais da sub-bacia hidrográfica do riacho Santa Rosa}

Por mais que se observe os sertões de forma homogênea, não se pode esquecer que estes, inseridos na depressão sertaneja, têm suas peculiaridades e características geoambientais variando significativamente a partir dos elementos que compõem a paisagem, como a geologia, geomorfologia, clima, recursos hídricos, solos e cobertura vegetal.

Além das variáveis naturais, as formas de uso e ocupação do solo são importantes na análise integrada dos elementos que compõem o cenário ambiental, onde a partir desses parâmetros seja possível delimitar e analisar os sistemas ambientais.

Para isso, propôs-se a classificação em cinco sistemas ambientais, os quais foram delimitados a partir de critérios geoambientais, levando em considerações variáveis como geomorfologia e classes de solos.

A geomorfologia evidencia-se como um critério clássico para a delimitação de unidades geoambientais. Segundo Souza (2007), a geomorfologia é uma variável que sintetiza o conjunto dos componentes geoambientais. Reconhecidamente, os limites do relevo e as feições do modelado são passíveis de uma delimitação mais precisa (SOUZA, 2007). 


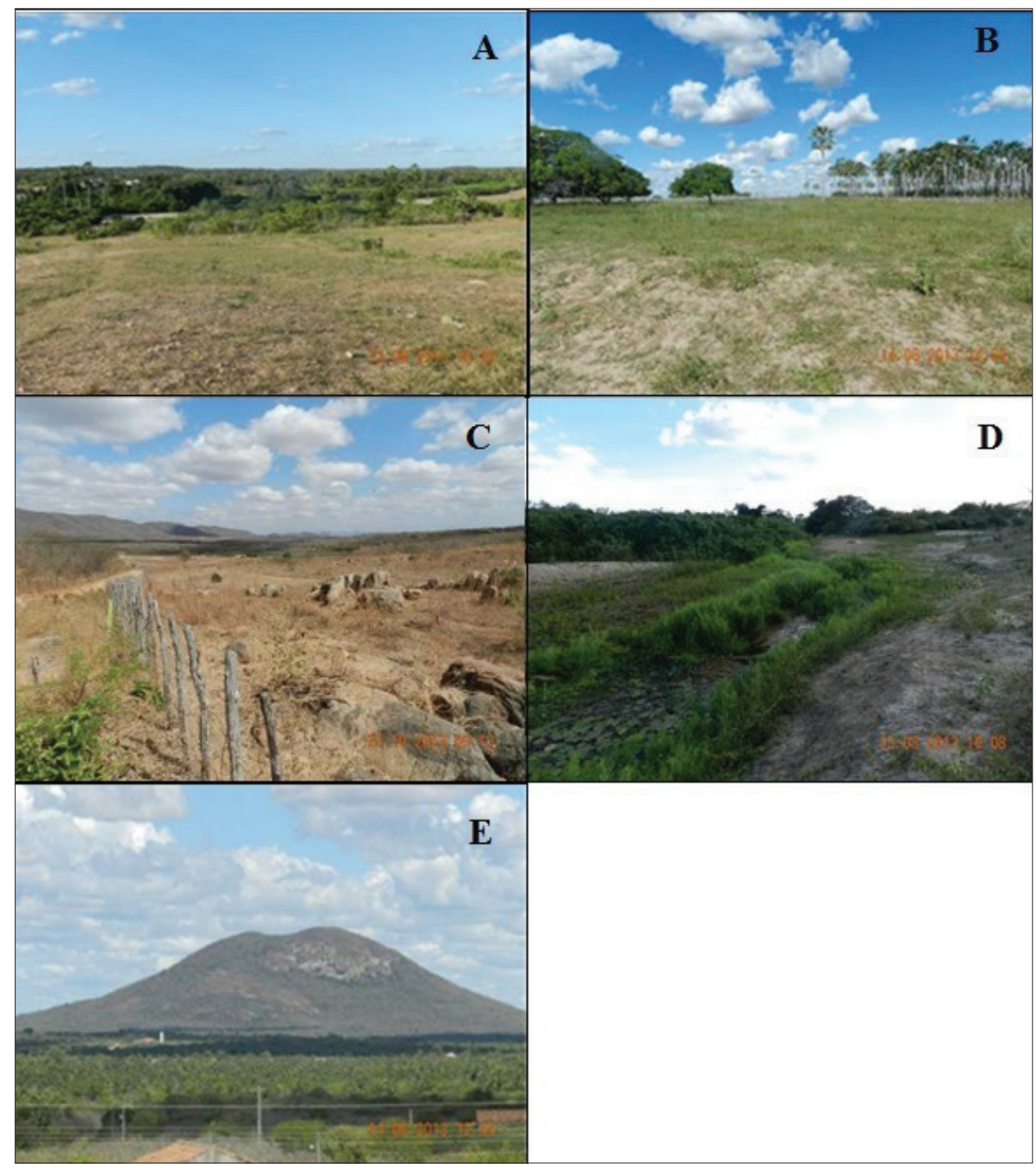

Figura 2. Representação dos sistemas ambientais na sub-bacia hidrográfica do riacho Santa Rosa.

Fonte: elaborado pelos autores.

Embora a análise geomorfológica seja preponderantemente um critério unificador para o ambiente, tal fato fica comprometido em decorrência da escala de trabalho e da própria dimensão da unidade geoambiental.

A área, de uma forma geral, não tem grandes variações no relevo, o que impossibilitaria uma delimitação adequada usando exclusivamente o critério geomorfológico. 
Outro critério utilizado na delimitação dos sistemas ambientais da sub-bacia do riacho Santa Rosa foram os parâmetros pedológicos. A utilização das classes de solo em conjunto com as formas de relevo tem uma capacidade de melhor sintetizar as variáveis geoambientais em áreas de depressão sertaneja.

Dessa forma, foram delimitados cinco Sistemas Ambientais na sub-bacia hidrográfica do riacho Santa Rosa: 1- sertões moderadamente dissecados de Jaguaretama; 2 - sertões pediplanados de Morada Nova; 3- planície ribeirinha e áreas de inundação sazonal; 4 - tabuleiros interiores com coberturas colúvio-eluviais detríticas e 5 - cristas residuais e inselbergs. A seguir, tem-se a caracterização de cada um deles.

\section{Sertões moderadamente dissecados de Jaguaretama (Figura 2C)}

Este sistema ambiental ocupa aproximadamente $293 \mathrm{~km}^{2}$ da sub-bacia hidrográfica do riacho Santa Rosa, ou seja, 43,4\% da área total. É composta essencialmente por rochas metamórficas do Complexo Jaguaretama, a destacar os ortognaisses. No extremo oeste da área é possível observar uma configuração estrutural associada à falha de Orós, que localmente representa um divisor de águas, apresentando uma paisagem com conjuntos de cristas alinhadas em direção N-S.

O relevo é suave-ondulado a ondulado, com declividade de 3\% a 8\%. Paisagem típica da Depressão Sertaneja, com sua superfície truncada pela morfogênese mecânica, predominando rampas de pedimentação que convergem para os fundos de vales.

Os níveis altimétricos variam de 140 a 240 metros, com uma variedade de solos que se configura como um grande mosaico na área de estudo. Nos níveis altimétricos mais elevados ha ocorrência de Luvissolos associados aos Neossolos Litólicos, além de apresentar manchas de Neossolos Regolíticos e Argissolos Vermelho-Amarelos Eutróficos.

Na medida em que o declive fica menos acentuado, a ocorrência de Planossolos associados aos Neossolos Litólicos e afloramentos se acentua.

Do ponto de vista vegetacional é possível observar a ocorrência de caatinga arbustiva densa e outra de configuração mais aberta. A primeira está associada às áreas de menor acesso por parte das populações locais; a segunda, com uma abrangência espacial maior, resquício da descaracterização desta em detrimento da produção de energia através da lenha e expansão da pecuária extensiva.

\section{Sertões pediplanados de Morada Nova (Figura 2A)}

Este sistema ambiental, juntamente com o anterior, ocupa a maior área da subbacia do riacho Santa Rosa, com uma área de $234,9 \mathrm{~km}^{2}$, correspondendo a $34,8 \%$ da sua área. É composta predominantemente por rochas metamórficas do Complexo Jaguaretama e em menor ocorrência, por rochas graníticas da Suíte Granitoide Itaporanga.

O relevo é suave-ondulado, com declividade de 3\% a $8 \%$. Paisagem preponderante de Depressão Sertaneja com superfície truncada pela morfogênese mecânica, predominando rampas de pedimentação com convergência para os fundos de vales. 
Esse sistema ambiental é caracterizado por ser uma superfície aplainada por processos de pediplanação, com declives mais suaves em relação à unidade anterior. O padrão de drenagem é caracterizado por ser dendrítico e subdendrítico, com rios intermitentes sazonais.

Os níveis altimétricos variam de 60 a 140 metros, com uma variedade de solos que depende dos condicionantes locais. Devido às características do relevo local há a predominância de Planossolos associados a Neossolos Litólicos, além da presença de afloramentos rochosos e caos de blocos.

A cobertura vegetal é caracterizada pela ocorrência de caatinga arbustiva aberta com alto grau de alteração por parte das atividades econômicas locais como a pecuária extensiva e o extrativismo vegetal.

\section{Planície ribeirinha e áreas de inundação sazonal (Figura 2D)}

Referem-se às áreas onde os processos fluviais de caráter deposicional preponderam, ocupando uma área de $86,8 \mathrm{~km}^{2}$, correspondendo a $13 \%$ da área da subbacia do riacho Santa Rosa. Dessa forma pode-se constatar a grande relevância desse sistema em relação aos anteriores, tendo em vista potencialidades voltadas à agricultura local.

Tal fato está associado à ocorrência de Neossolos Flúvicos que margeiam os canais fluviais. Essa característica acentua a maior fertilidade dos solos locais, possibilitando o cultivo de diversas variedades, a destacar o milho e o feijão.

Ao longo das calhas fluviais há ocorrência de aluviões quaternárias que se acumulam ao longo de toda a sub-bacia, destacando-se as áreas do médio e baixo curso do referido sistema.

A cobertura vegetal é composta por vegetação de várzea, caracterizada pela ocorrência da mata ciliar de carnaúba associada predominantemente aos Neossolos Flúvicos e Planossolos, localizadas em setores deprimidos passíveis de encharcamento natural no período chuvoso.

\section{Tabuleiros interiores com coberturas colúvio-eluviais detríticas (Figura 2F)}

Sistema ambiental caracterizado pela ocorrência de áreas planas a suave onduladas, com declividade de $0 \%$ a $3 \%$. Possui área total de $33,5 \mathrm{~km}^{2}$, correspondendo a $4,9 \%$ do total da área da sub-bacia do riacho Santa Rosa. Geologicamente é constituída por sedimentos argilo-arenosos e areno-argilosos cenozóicos.

O relevo é plano, correlacionado geomorfologicamente com os tabuleiros interiores. Os níveis altimétricos variam de 80 a 120 metros, sem grandes variações evidentes no interior da depressão sertaneja local, o que leva a considerar os mesmos mecanismos de gênese na estrutura das paisagens, comandados essencialmente por climas semiáridos.

Do ponto de vista pedológico, predominam os Argissolos Vermelho-Amarelos Distróficos associados aos Neossolos Quartzarênicos e Neossolos Regolíticos. O padrão 
de drenagem é caracterizado por ser subdendrítico e paralelo, com rios intermitentes sazonais.

A cobertura vegetal é caracterizada pela ocorrência da vegetação subcaducifólia de tabuleiro. A vegetação nativa foi quase totalmente desmatada para dar lugar aos pastos para o gado.

\section{Cristas residuais e inselbergs (Figura 2E)}

Menor unidade representativa dos sistemas ambientais da sub-bacia do riacho Santa Rosa. Esta unidade compreende as cristas residuais e inselbergs, com uma área de $5,9 \mathrm{~km}^{2}$, correspondendo a $0,8 \%$ da área da sub-bacia.

Esse sistema ambiental é caracterizado pela ocorrência de níveis altimétricos mais elevados, a destacar a serra da Santa Marta, inselberg que rompe a monotonia da depressão sertaneja e as cristas residuais que se situam no extremo oeste da bacia.

Os níveis altimétricos dessas áreas giram em torno dos 240 metros, com a ocorrência de Neossolos Litólicos associados aos afloramentos rochosos. A vegetação é composta predominantemente por uma caatinga arbustiva aberta.

Pelo difícil acesso e condições ambientais desfavoráveis em relação aos sistemas ambientais anteriores, este último é pouco explorado, apresentando limitações para as atividades agroextrativistas.

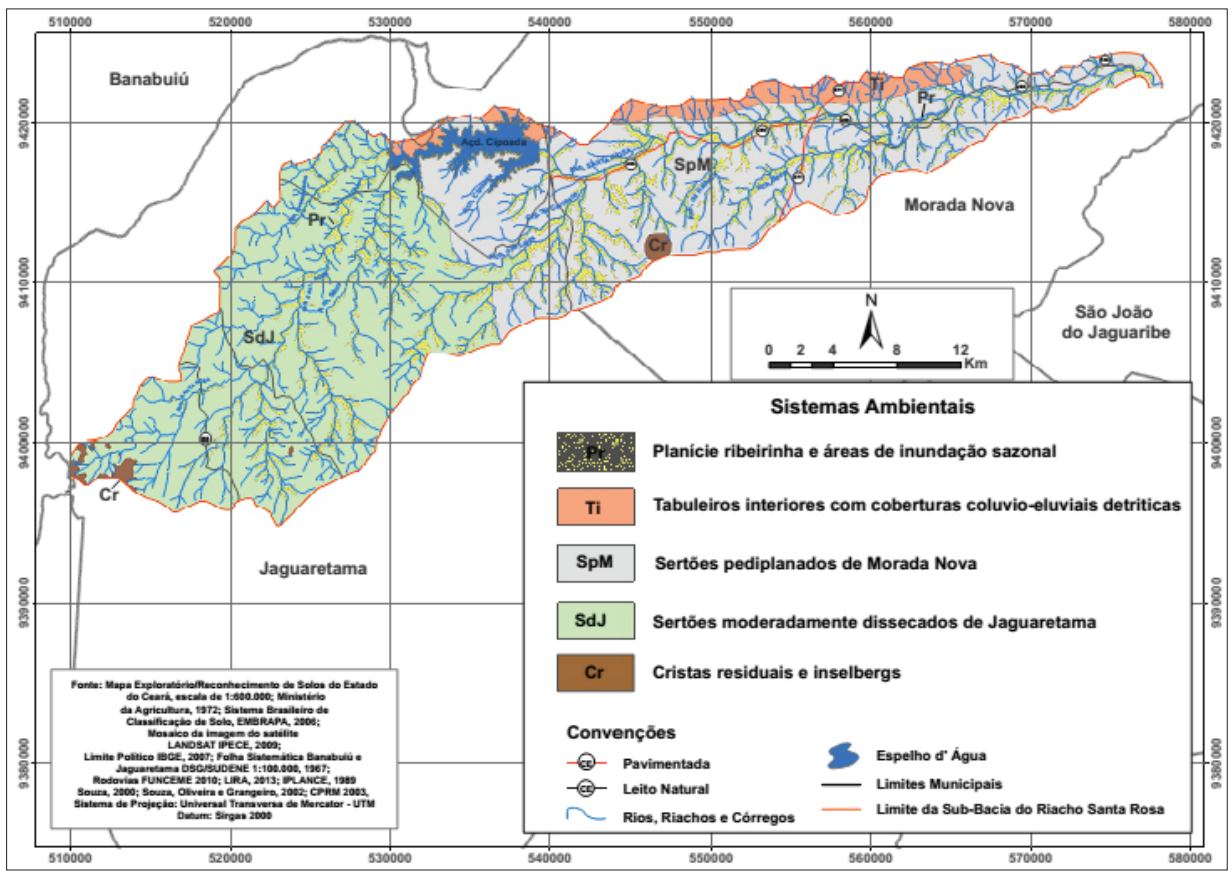

Figura 3. Sistemas ambientais da sub-bacia hidrográfica do riacho Santa Rosa 


\section{Indicadores de desertificação na sub-bacia hidrográfica do Riacho Santa Rosa}

Vulnerabilidade ambiental e os indicadores geobiofísicos

Nesse seção é realizada o estudo da sub-bacia hidrográfica com base na análise dos indicadores geobiofísicos baseados na metodologia de Abraham e Beekman (2006) e Oliveira $(2003,2012)$, em que são destacados alguns parâmetros como geologia, geomorfologia, cobertura vegetal, solos, erosão e condições climáticas.

A partir desses indicadores é possível estabelecer uma análise não só qualitativa, mas também quantitativa dos parâmetros geoambientais da sub-bacia, visando detectar quais as variáveis desses indicadores melhor se encaixam na realidade geoambiental e socioeconômica da área de pesquisa.

Inicialmente realizou-se uma análise da vulnerabilidade ambiental da área, com o objetivo de classificar os ambientes de acordo com a proposta de Souza (2000), em que se podem estabelecer parâmetros para determinar a estabilidade e instabilidade do ambiente, proposta com base nos estudos de Tricart (1977).

Com base na relação pedogênese/morfogênese, além do grau de interferência humana sobre os recursos naturais, principalmente a cobertura vegetal, Souza (2000) estabelece que os ambientes podem ser assim classificados: ambientes estáveis, transição (intergrades), instáveis e fortemente instáveis. Na figura 4 pode-se observar o grau de vulnerabilidade ambiental dos sistemas ambientais da sub-bacia hidrográfica do riacho Santa Rosa.

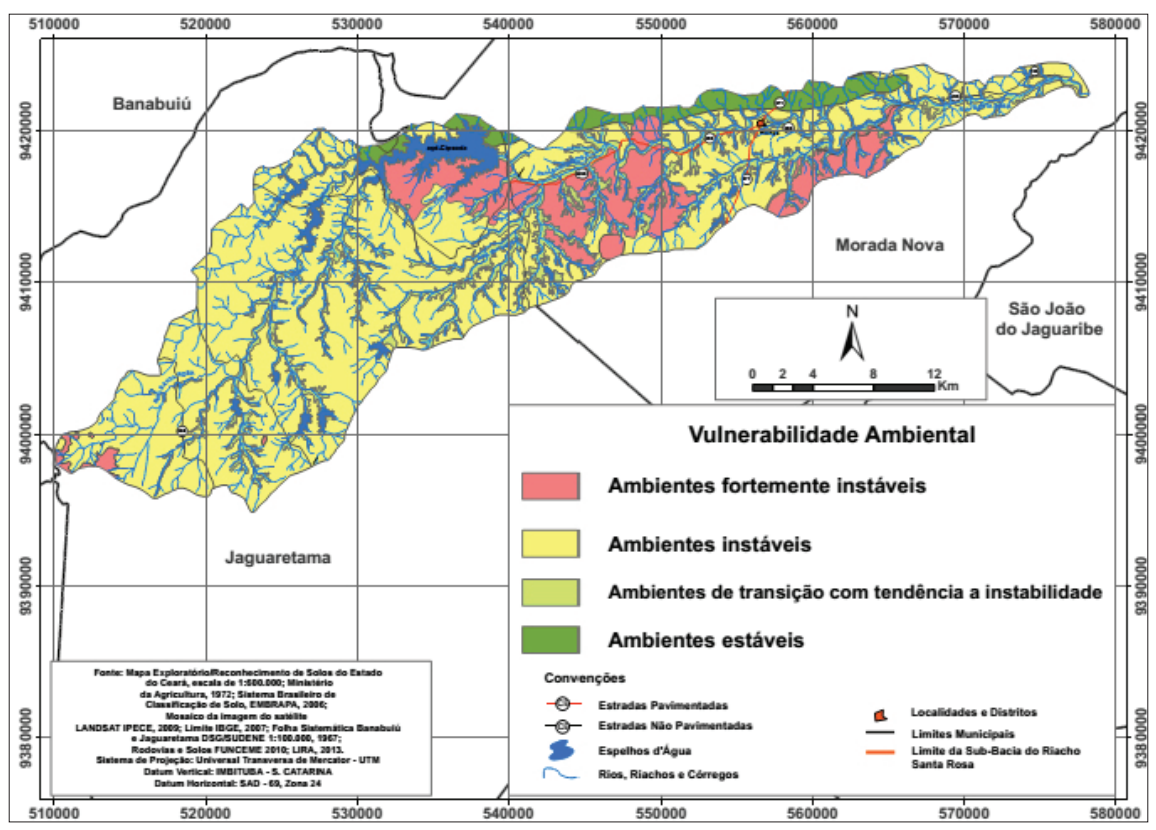

Figura 4. Vulnerabilidade ambiental da sub-bacia hidrográfica do riacho Santa Rosa Fonte: elaborado pelos autores. 
Com a espacialização dos sistemas ambientais, assim como a relação estabelecida com o uso e ocupação e a vulnerabilidade ambiental, buscou-se a relação dessas variáveis com os indicadores geobiofísicos de desertificação, ou seja, uma maneira de estabelecer níveis de desertificação para a sub-bacia, utilizando os sistemas ambientais como base de análise.

Quadro 1. Indicadores geobiofísicos de desertificação dos sistemas ambientais

\begin{tabular}{|l|c|c|c|c|c|c|c|}
\hline & IGBD1 & IGBD2 & IGBD3 & IGBD4 & IGBD5 & IGBD6 & \\
\hline $\begin{array}{l}\text { Sertões moderadamente } \\
\text { dissecados de Jaguaretama }\end{array}$ & 1 & 3 & 4 & 3 & 4 & 2 & $\mathbf{2 , 8 3}$ \\
\hline $\begin{array}{l}\text { Sertões pediplanados de } \\
\text { Morada Nova }\end{array}$ & 1 & 4 & 2 & 3 & 4 & 2 & $\mathbf{2 , 6 6}$ \\
\hline $\begin{array}{l}\text { Planícies ribeirinhas e áreas de } \\
\text { inundação sazonal }\end{array}$ & 5 & 4 & 3 & 4 & 4 & 2 & $\mathbf{3 , 6 6}$ \\
\hline $\begin{array}{l}\text { Tabuleiros interiores com } \\
\text { coberturas colúvio-eluviais } \\
\text { detríticas }\end{array}$ & 4 & 5 & 2 & 5 & 3 & 2 & $\mathbf{3 , 5 0}$ \\
\hline Cristas residuais e inselbergs & 2 & 2 & 1 & 1 & 5 & 2 & $\mathbf{2 , 1 6}$ \\
\hline Média & 2,6 & 3,6 & 2,4 & 3,2 & 4 & 2 & $\mathbf{2 , 9 6}$ \\
\hline Desvio Padrão & 1,67 & 1,01 & 1,01 & 0,94 & 0,63 & 0 & $\mathbf{0 , 5 4}$ \\
\hline
\end{tabular}

Fonte: Costa (2014).

A partir dos dados foi gerado o mapa (figura 5), onde é possível perceber que existem dois grupos distintos quando é analisado o grau de geobiofísico de desertificação da sub-bacia do Riacho Santa Rosa.

O primeiro grupo, com valores de 2,16 a 2,83 representando os sistemas ambientais: cristas residuais e inselbergs, sertões moderadamente dissecados de Jaguaretama e sertões pediplanados de Morada Nova, e um segundo grupo, representado pelos valores de 3,50 e 3,66 representados pelos sistemas ambientais: tabuleiros interiores com coberturas colúvio-eluviais detríticas e planícies ribeirinhas e áreas de inundação sazonal.

Pode-se perceber que a relação dos dois grupos apresenta comportamentos diferenciados, frente à composição do IGBD. Os grupos mais vulneráveis, com valores de 2,16 a 2,83 apresentam características que irão atribuir características frágeis aos ambientes, como os solos rasos, cobertura vegetal em estado de degradação elevado e condições hídricas insuficientes.

Condições diferentes terão os outros dois sistemas ambientais, com valores de 3,50 a 3,66, que terão características favoráveis quanto as potencialidades do ambiente. A presença de condições hídricas favoráveis, solos profundos e férteis e uma cobertura vegetal medianamente conservada, atribuem condições favoráveis para a ocupação e manutenção das condições de uso e ocupação desses sistemas ambientais. 


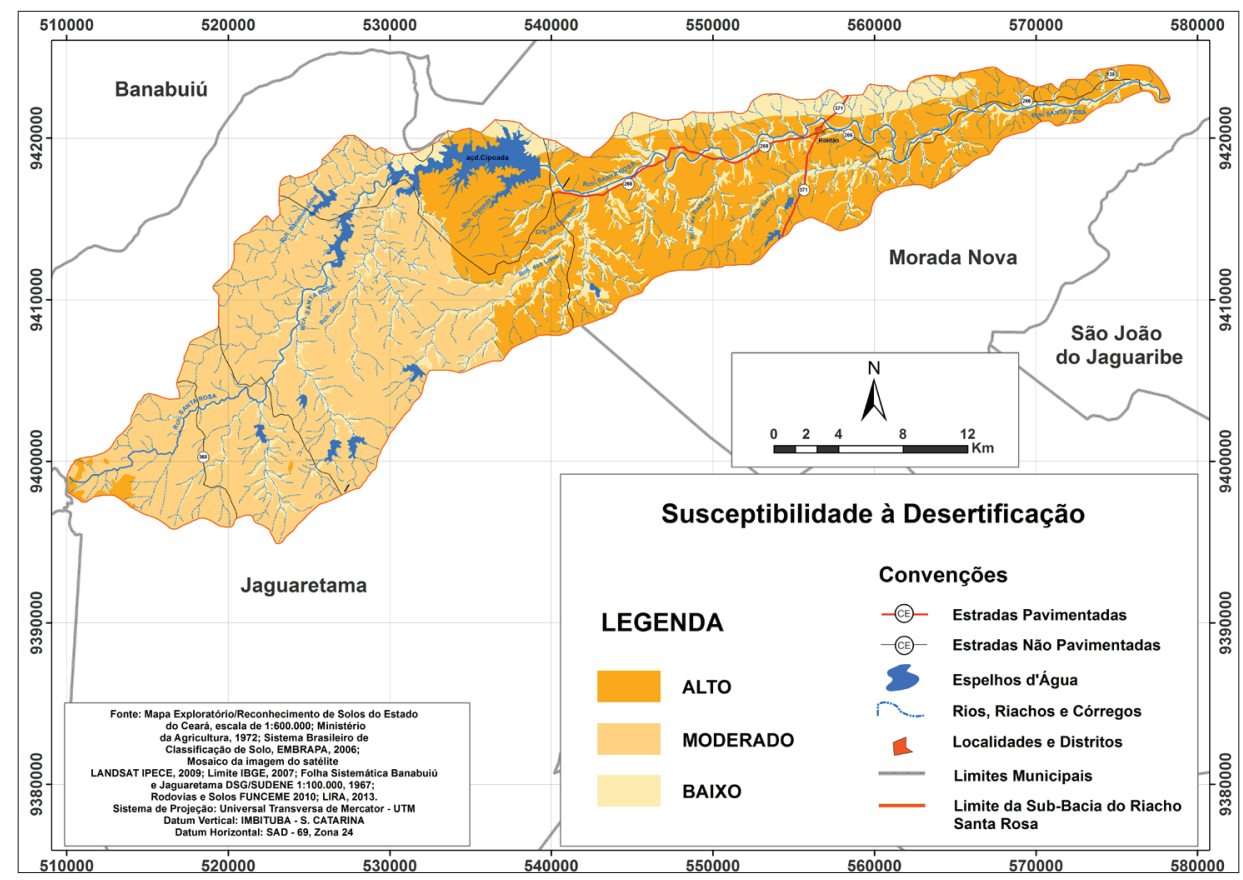

Figura 5. Susceptibilidade à desertificação da sub-bacia hidrográfica do riacho Santa Rosa Fonte: elaborado pelos autores.

\section{Considerações finais}

O processo de uso e ocupação da sub-bacia hidrográfica do Riacho Santa Rosa não é um processo que foge à regra das grandes áreas semiáridas do Nordeste brasileiro, mas que merece destaque para as suas devidas particularidades.

$\mathrm{O}$ estudo através dos sistemas integrados proporcionou visualizar não apenas a condição física da sub-bacia, mas principalmente perceber como os agentes que compõem o arcabouço unitário se comportam quando se realiza o exercício da integração dos elementos.

Diante disso, fica evidente a contribuição dos estudos integrados na análise da paisagem, subsidiando pesquisas que devem ser consultadas para o melhor gerenciamento e planejamento do ambiente. Embora muitas vezes os trabalhos sejam negligenciados ou simplesmente engavetados, nosso objetivo é continuar aplicando os conhecimentos acadêmicos de forma prática e dessa maneira aplicá-los no ordenamento do território.

A sub-bacia do Riacho Santa Rosa proporcionou um exercício da aplicação dos estudos integrados, usando da bacia hidrográfica como célula de pesquisa. A partir das análises fica evidente que a degradação ambiental é tema relevante no âmbito acadêmico, principalmente quando se refere às áreas dos sertões cearenses. 
Outro aspecto interessante e que não pode ser desconsiderado é o caminho metodológico que a pesquisa transcorreu. A configuração de uma área de aproximadamente $675 \mathrm{~km}^{2}$, majoritariamente plana a suave ondulada, com destaque para a ocorrência de poucas cristas residuais, impossibilitou a utilização da geomorfologia como fator majoritário dos estudos de base. Para suprir essa carência o mosaico de solo da larga depressão sertaneja local foi utilizado como parâmetro para as análises posteriores.

A análise dos sistemas ambientais, com suporte dos estudos setoriais foi ponto fundamental para a compreensão da dinâmica da sub-bacia, principalmente no que se refere aos aspectos geoambientais. Nesse sentido, o referido mapa foi basilar à análise posterior, ou seja, o nível de vulnerabilidade e a susceptibilidade à desertificação.

A partir da análise do uso e ocupação da sub-bacia, fica evidenciado o agroextrativismo como forma majoritária de ocupação e manuseio do solo local, o que vem provocado a maior parte dos danos à cobertura vegetal e consequentemente aos horizontes superficiais do solo.

A mata ciliar apresentou-se moderadamente conservada, e a vegetação de caatingas apresentou graus de conservação, variando de moderadamente conservada a fortemente degradada. Importante ponto foi a mancha que apresentou a agropecuária como destaque, fato esse relacionado às condições do substrato local, com a presença dos tabuleiros interiores, com ocorrência de solos profundos (Argissolos).

A vulnerabilidade da sub-bacia foi importante marco para identificar as áreas mais vulneráveis do ponto de vista ambiental. Os sertões pediplanados de Morada Nova apresentaram as áreas mais vulneráveis (fortemente instáveis), pelo fato de a cobertura vegetal estar bastante alterada em setores desse sistema.

As planícies fluviais e o restante das áreas dos sertões apresentaram, respectivamente, ambientes de transição com tendência à instabilidade e ambientes instáveis. As planícies foram compreendias como tendentes à instabilidade, mas não desconsiderando suas potencialidades locais, no que se refere às condições hídricas e pedológicas.

A área dos tabuleiros interiores com coberturas colúvio-eluviais detríticas, apesar de um médio grau de desmatamento, apresentou, em relação às outras áreas, condições mais estáveis do ponto de vista ambiental.

A susceptibilidade à desertificação evidencia o grau de vulnerabilidade dos sistemas ambientais à desertificação, e que tem como resultados parâmetros interessantes no que se refere a escalas de alto, moderado e baixo, elencados para a área.

A partir da aplicação dos indicadores geobiofísicos de desertificação, se constatou que os sertões pediplanados de Morada Nova apresentaram os valores mais baixos, ou seja, do ponto de vista das potencialidades, foi o sistema que apresentou o maior grau de susceptibilidade à desertificação. Fato esse já visualizado quando da análise do mapa de uso e ocupação e vulnerabilidade ambiental. Os sertões moderadamente dissecados de Jaguaretama apresentaram grau moderado, devido as suas condições ambientais estarem mais favoráveis que o sistema anterior. 
As planícies ribeirinhas e áreas de inundação sazonal apresentaram grau de susceptibilidade baixo, fato esse constatado pelas potencialidades locais, que mesmo sendo consideradas áreas de intenso uso, são ao mesmo tempo sistemas que abrigam potencialidades para a preservação das práticas agricultáveis mais eficientes.

Os tabuleiros interiores com coberturas colúvio-eluviais detríticas, apresentaram da mesma forma grau baixo, devido principalmente as suas condições de solos e cobertura vegetal, o que contribuiu para o melhor aproveitamento dos recursos naturais desse sistema.

A análise de todos esses componentes proporcionou uma visão das condições geoambientais da sub-bacia, desde os seus elementos setoriais, passando pelos sistemas ambientais, até chegar à vulnerabilidade e a susceptibilidade à desertificação. Importante etapa essa para o pesquisador aprimorar suas ferramentas para a análise da paisagem.

A prática e o aprimoramento da análise dos sistemas ambientais é um exercício constante, pois fica claro a contribuição para o estudo no âmbito da Geografia. A bacia hidrográfica nesse sentido se torna uma aliada, pois sua concepção já evidencia a integração dos elementos físicos.

\section{Referências}

AB'SABER, A.N. Problemática da desertificação e da savanização no Brasil Intertropical. Geomorfologia, n.53, São Paulo, IGEOG, 1977.

ABRAHAM, E.M.; BEEKMAN, G.B. Indicadores de la desertificación para América del Sul. IICA-BID ATN JF. Mendoza, Argentina: LaDyOT/IADIZA/CONICEF/IICA, 2006.

BEEKMAN, G.B. El programa combate a la desertificación y mitigación de los efectos de la sequía em América del Sur IICA / BID. In: ABRAHAM, E.M; BEEKMAN, G.B. (orgs). Indicadores de la desertificación para América del Sur. Argentina. Editora Martín Fierro, 2006.

BERTAlANFFY, L.V. Teoria Geral dos Sistemas. Petrópolis: Vozes, 1973.

BERTRAND, G. Paisagem e geografia física global: esboço metodológico. Caderno de ciências da terra, n.13, 1971.

BOTELHO, R. G. M.; SILVA, A. S. da. Bacia Hidrográfica e Qualidade Ambiental. In: VITTE, Antônio C.; GUERRA, Antônio J. T. (orgs). Reflexões sobre a Geografia Física no Brasil. 2 ed. Rio de Janeiro: Bertrand Brasil 2004.

BRASIL. Ministério do Meio Ambiente (MMA). Programa de Ação Nacional de Combate à Desertificação e Mitigação dos Efeitos da Seca. PAN-BRASIL. Edições MMA, Brasília, 2004. 
CEARÁ. Assembleia Legislativa. Caderno regional da sub-bacia do Banabuiú / Conselho de Altos Estudos e Assuntos Estratégicos. SANTANA, E.W. de (Coordenador). - Fortaleza: INESP, 2009.

CEARÁ (Estado). Programa de Ação Estadual de Combate à Desertificação e Mitigação dos Efeitos da Seca, PAE-CE. Fortaleza: Ministério do Meio Ambiente / Secretaria dos Recursos Hídricos, 2010.

CONTI, J.B. Desertificação nos Trópicos: proposta de metodologia aplicada ao Nordeste Brasileiro. Tese de Livre Docência - USP, São Paulo, 1995.

COSTA, L. R. F. Estruturação Geoambiental e Susceptibilidade à Desertificação na Sub-bacia Hidrográfica do Riacho Santa Rosa - Ceará. Dissertação de Mestrado. Universidade Federal do Ceará, Fortaleza, 2014.

CPRM - Serviço geológico do Brasil. Mapa geológico do Estado do Ceará. Escala 1:500.000, Ceará. CPRM, 2003.

CHIRISTOFOLETTI, A. Modelagem de Sistemas Ambientais. São Paulo: Ed. Edgard Blucher, 1999.

GUERRA, A.T.; GUERRA, A. J. T. Novo Dicionário Geológico-Geomorfológico. Rio de Janeiro: Bertrand Brasil, 1997.

IBGE. Instituto Brasileiro de Geografia e Estatística. Manual técnico de geomorfologia/ $I B G E$, Coordenação de Recursos Naturais e Estudos Ambientais. - 2. ed. - Rio de Janeiro : IBGE, 2009.

LORANDI, R; CANÇADO, C. J. Parâmetros físicos para gerenciamento de bacias hidrográficas. In: SCHIAVETTI, A; CAMARGO, A. (editores). Conceitos de Bacias Hidrográficas. Ilhéus - BA: Editora da UESC, 2005.

MATALLO JÚNIOR, H. A desertificação no mundo e no Brasil. In: SCHENKEL, C.S; JÚNIOR, H. M. (org.). Desertificação. Brasília: UNESCO, 1999.

OLIVEIRA, V. P. V. A Problemática da Degradação dos Recursos Naturais no Domínio dos Sertões Secos do Estado do Ceará-Brasil. In: SILVA, J.B; DANTAS, E.W.C. e MEIRELES, A.J.A. (org.). Litoral e Sertão: Natureza e Sociedade no Nordeste Brasileiro. Fortaleza: Expressão Gráfica, 2006.

PIRES, J. S. R; SANTOS, J. E. Bacias Hidrográficas: integração entre o meio ambiente e desenvolvimento. Revista Ciência Hoje: Águas do Brasil: má utilização e falta de planejamento, vol. 19, n 110. SBPC, 1995. p. 40-45.

; DEL PRETTE. A utilização do conceito de bacia hidrográfica para a conservação dos recursos naturais. In: SCHIAVETTI, A; CAMARGO, A. (editores). Conceitos de Bacias Hidrográficas. Ilhéus - BA: Editora da UESC, 2005.

PROJETO RADAMBRASIL. FOLHA SB.23/24 JAGUARIBE/NATAL: geologia, geomorfologia. Rio de Janeiro. 1981. 
RÊGO, A.H. Os sertões e os desertos: o combate à desertificação e a política externa brasileira. Brasília: FUNAG, 2012.

SAlES, M. C. L; OLIVEIRA, J. G. B. Análise da Degradação Ambiental no Núcleo de Desertificação de Irauçuba. In: SILVA, J.B; DANTAS, E.W.C. e MEIRELES, A.J.A. (org.). Litoral e Sertão: Natureza e Sociedade no Nordeste Brasileiro. Fortaleza: Expressão Gráfica, 2006.

SANTOS, J.O; SOUZA, M.J.N. Abordagem geoambiental aplicada à análise da vulnerabilidade e dos riscos em ambientes urbanos. In: Boletim Goiano de Geografia. v.34. n. 2, 2014.

SOARES, A. M. L; LEITE, F. R. B; LEMOS, J. J. S; MARTINS, M. L. R; NERA, R. D. M; OLIVEIRA, V. P. V. de. Áreas degradadas suscetíveis aos processos de desertificação no Ceará. In: GOMES, M. G; SOUZA, H. R; MAGALHÃES, A. R. (org.). Desenvolvimento Sustentável no Nordeste. Brasília: IPEA:1995.

SOUZA, M.J.N. Contribuição ao estudo das unidades morfo-estruturais do Estado do Ceará. In: Revista de Geologia. Fortaleza: v.1. Edições Universidade Federal do Ceará, 1988.

SOUZA, M. J. N. Bases geoambientais e esboço do zoneamento geoambiental do Estado do Ceará. In: LIMA, L. C. (Org). Compartimentação territorial e gestão regional do Ceará. Fortaleza: Funece, 2000.

SOUZA, M. J. N; OLIVEIRA, V.P.V. Semi-árido do Nordeste do Brasil e o fenômeno da seca. IN: Hubp, J.L.e Inbar, M. (compiladores). Desastres Naturales em América Latina. Fondo de Cultura Econômica. México. 2002.

SOUZA, M. J. N; OLIVEIRA, V.P.V; GRANGEIRO, M.M.G. Análise Geoambiental. In: ELIAS, D. (Org.) O novo espaço da produção globalizada - o baixo Jaguaribe. Fortaleza: Funece, 2002.

SOUZA, M. J. N; SANTOS, J.O; OLIVEIRA, V.P.V. Sistemas ambientais e capacidade de suporte na bacia hidrográfica do rio Curu-Ceará: Revista Continentes. Ano 1. n.1, 2012.

SOUZA, M. J. N; OLIVEIRA, V. P. V. Análise ambiental - uma prática da interdisciplinaridade no ensino e na pesquisa. 2011. Disponível em: <http:/www. revistarede.ufc.br/revista/index.php/rede/article/viewArticle/168<. Acesso em $25 \mathrm{de}$ setembro de 2013.

. Compartimentação geoambiental do Ceará. In: SILVA, J. B; CAVALCANTE; T. DANTAS, E. (Org). Ceará: um novo olhar geográfico. Fortaleza: Edições Demócrito Rocha, 2007.

SUERTEGARAY, D. M. A. Desertificação: recuperação e desenvolvimento sustentável. In: GUERRA, A. J. T; CUNHA, S.B. (org.). Geomorfologia e Meio Ambiente. 2.ed. Rio de Janeiro: Bertrand Brasil, 1998. 
TEODORO, V. L. I.; TEIXEIRA, D.; COSTA, D. J. L.; FULLER, B. B. O conceito de bacia hidrográfica e a importância da caracterização morfométrica para o entendimento da dinâmica ambiental local. Revista UNIARA, v. 20, 2007.

TRICART, J. Ecodinâmica. Rio de Janeiro: IBGE, 1977. . Paisagem e Ecologia. Traduzido pelo Prof $^{\mathrm{D}}$ Carlos A. F. Monteiro, SP: Instituto de Geografia; USP, 1981.

Luis Ricardo Fernandes da Costa

Mestre e Doutorando em Geografia pela Universidade Federal do Ceará - UFC Integrante como pesquisador do LAPED (Laboratório de pedologia, análise geoambiental e desertificação) e do Laboratório de Geomorfologia.

Campus do Pici, Bloco 911 - Fortaleza/CE, Cep: 60440-900, Brasil. ricardogeoufc@yahoo.com.br

Vládia Pinto Vidal de Oliveira

Professora Associada II do Programa de Pós-Graduação em Geografia da Universidade Federal do Ceará - UFC

Coordenadora do LAPED (Laboratório de pedologia, análise geoambiental e desertificação).

Campus do Pici, Bloco 911 - Fortaleza/CE, Cep: 60440-900, Brasil.

vladia.ufc@gmail.com

Recebido para publicação em janeiro de 2016

Aprovado para publicação em junho de 2016 